Araştırma Makalesi/Research Article

\title{
Bazı Bitki Ekstraktlarının İki Noktalı Kırmızıörümcek, Tetranychus urticae Koch Üzerine İnsektisit Etkisinin Belirlenmesi
}

\author{
İsmail Kasap* \\ Şahin Kök \\ Çanakkale Onsekiz Mart Üniversitesi, Ziraat Fakültesi, Bitki Koruma Bölümü, 17100 - Çanakkale \\ *Sorumlu yazar: ikasap@comu.edu.tr
}

Geliş Tarihi: 01.04.2019

Kabul Tarihi: 21.06.2019

\section{Öz}

Bu çalışmada, Lepidium sativum L., Eruca vesicaria Mill., Mentha pulegium L., Ocimum basilicum L. ve Rosmarinus officinalis L. ekstraktlarının İki noktalı kırmızıörümcek, Tetranychus urticae Koch'nin nimf ve ergin dönemleri üzerine insektisit etkisi yaprak disk daldırma yöntemi kullanılarak belirlenmiştir. Denemelerde ekstraktların \%1, 3, 6, 12 konsantrasyonları kullanılmış ve sayımlar uygulamadan 2, 6, 24, 48, 72 ve 96 saat sonra yapılmıştır. Denemeler her konsantrasyon için 5 tekerrür ve her tekerrürde 10 birey olacak şekilde gerçekleştirilmiştir. T. urticae'nin hem nimf hem de ergin dönemlerinde en yüksek ölüm oranları $R$. officinalis ekstraktının \%12'lik konsantrasyonunda sırasıyla \%68 ve \%96 olarak belirlenmiştir. Bitki ekstraktlarının farklı konstarasyonlarının yaprak disk daldırma yönteminin kullanıldığı denemelerde ergin bireyler üzerinde etkisi $R$. officinalis $>M$. pulegium $=O$. basilicum $>$ E. vesicaria $>$ L. sativum olarak sıralanmıştır. Sonuç olarak, İki noktalı kırmızıörümcek ile mücadelede bu çalışmada kullanılan bitki ekstraktlarının pestisitlere karşı alternatif bir yöntem olarak kullanılabileceği düşünülmektedir.

Anahtar Kelimeler: Bitki ekstrakt1, Tetranychus urticae, Nimf, Ergin, İnsektisit etki

\section{Determination of the Insecticide Effect of Some Plant Extracts on Two Spotted Spider Mite, Tetranychus urticae Koch}

\section{Abstract}

In this study, the insecticide effect of Lepidium sativum L., Eruca vesicaria Mill., Mentha pulegium L., Ocimum basilicum L. and Rosmarinus officinalis L. extracts on nymphal and adult stages of two spotted spider mite, Tetranychus urticae Koch were determined using leaf disk dipping methods. In the tests, 1, 3, 6 and 12\% concentrations of the extracts were used and counting was carried out 24th, 48th, 72nd and 96th hours after the treatments. The tests were prepared such that each concentration had 5 replications and each replication included 10 individuals. The highest mortality rates of nymph and adult individuals of T. urticae were recorded as $68 \%$ and $96 \%$, respectively, at $12 \%$ concentration of $R$. officinalis. In the tests using leaf disk dipping method on adult females of T. urticae, the effects of the extracts were arranged as R. officinalis $>M$. pulegium $=O$. basilicum $>E$. vesicaria $>$ L. sativum. As a result, plant extracts used in this study are thought to be used as an alternative method to pesticides for control of two-spotted spider mites.

Keywords: Plant extract, Tetranychus urticae, Nymph, Adult, Insecticide effect.

\section{Giriş}

Tüm dünyada olduğu gibi ülkemizde de tarımsal üretimde ekonomik kayılara sebep olan, verim ve kaliteyi sınırlayan en önemli etkenlerin başında hastalık, zararlı ve bazen de yabancı otlar gelmektedir. Ekonomik olarak üretimi yapılan bitkilerde verim ve kalitede azalmalara sebep olan zararlıların mücadelesinde en etkin yöntemlerden biri kimyasal bileşiklerin kullanımıdır. Pestisit olarak da adlandırılan bu bileşiklerin bilinçsiz ve yoğun miktarlarda kullanımının hem çevre hem de insan sağlığı üzerine kısa ve uzun vadede ciddi olumsuz etkileri bulunmaktadır. Kimyasal bileşiklerin bilinçsiz bir şekilde kullanılması çevre açısından değerlendirildiğinde ciddi seviyede su ve toprak kirliliğine sebep olmakta ve bu kirliliğe maruz kalan insanlarda düşük ile sonuçlanan hamilelik, ishal, hepatit A ve tifo gibi önemli hastalıklar görülmektedir (Cutler ve Miller, 2005; Grant ve ark., 2012).

Tarımsal üretimde kimyasal bileşiklerin yoğun kullanımının kısa ve uzun vadede sebep olduğu ciddi sonuçlar nedeniyle tarımsal ürünlerde önemli ekonomik kayıplar meydana getiren hastalık, zararlı ve yabancı otlar ile mücadelede alternatif yöntemler arayışı ortaya çıkmıştır. Çevre ve insan sağlığına duyarlı çalışmaların sonucu olarak tarımsal zararlılara karşı spesifik etkiler gösteren ve 
genellikle fizyolojik yollarla zararlılara etki ederek onları öldüren bileşiklerin kullanıldığı bitkilerden elde edilen ekstraktlar, kimyasal bileşiklere alternatif olacak yeni bir mücadele yöntemi olarak ortaya çıkmıştır (Erdoğan ve Toros, 2005). Bitkisel ekstraktların doğada zaten hâlihazırda var olmaları ve doğal döngü içerisinde bir yere sahip olmaları gibi nedenlerden dolayı bu bileşiklerin tarımsal zararlılar üzerindeki mücadeleye yönelik etkilerini araştıran çalışmaların sayısı son yıllarda önemli ölçüde artış göstermiştir. Yapılan çalışmalar ile yaklaşık olarak 2400 bitkiden elde edilen farklı ekstraktların tarımsal zararlılar üzerinde insektisit etkisinin bulunduğu belirlenmiştir. Bu bitkilerden ise yaklaşı 100 türden elde edilen ekstraktlarda kırmızı örümceklerin mücadelesinde etkin sonuçlar vermektedir (Yang ve ark., 2007) Bitkilerden elde edilen ekstraktlar kimyasal mücadeleye karş1 kullanılma potansiyeli en yüksek olan seçeneklerden biridir. Azadirachta indica A.Juss., Tanacetum vulgare L., Artemisia absinthium L., Satoreja hortensis, Calotropis porcera ve Nerium oleander gibi bitkilerden elde edilen ekstraktlar bitkisel akarisitler olarak belirtilmektedir (Chiasson ve ark., 2001; Aslan ve ark., 2004; Martinez-Villar ve ark., 2005; Islam et al., 2008; Derbalah et al., 2013). Ayrica, bitkisel ekstraktların içinde barındırdığı bazı sekonder metabolitler tarımsal üretimde ekonomik kayıplara sebep olan zararlı böceklere karşı beslenmeyi engelleyici, uzaklaştırıcı ve yumurta açılımını engelleyici etkiler de göstermektedir (Tomczyk ve Suszko, 2011; Kök ve ark., 2016). Bitkisel ekstrakların içerisinde bulunan sekonder metabolitler yapılan araştırmalarda memelilere, balıklara ve insanlara karşı çok düşük seviyede toksik etki gösterdiğinden dolayı zararlıların kontrolündeki en uygun seçeneklerden biridir (Liu ve ark., 2000).

İki noktalı kırmızı̈rümcek, Tetranychus urticae Koch, dünya çapında kültür bitkilerinde ekonomik olarak önemli derecede kayıp meydana getirebilen polifag zararlıların başında gelmektedir. T. urticae domates, fasulye, hıyar ve patlıcanın içerisinde olduğu 150 tanesi ekonomik olarak üretilen ve pazarlanan, yaklaşık 1200 bitki türü üzerinde zarar meydana getirmektedir (Jeppson ve ark., 1975; Zhang, 2003). T. urticae'nin bitkilerin özsuyu ile beslenmesi sonucunda yapraklarda kıvrılma ve sararma oluşarak yaklaşık \%40-60 oranında ürün kaybı ve kalitede önemli oranda azalma meydana gelmektedir (Thomas, 1969).

T. urticae'nin mücadelesinde öncelikli olarak spiromesifen, pyridaben ve tebufenpyrad gibi etkili maddelere sahip geleneksel akarisitler kullanılmaktadır. Bu pestisitler zararlı ile mücadelede oldukça etkili olsa da uzun yıllar boyunca yoğun olarak kullanımı, zararlının kısa hayat döngüsü ve hızlı çoğalması gibi faktörlerden dolayı hem zararlının bu pestisitlere karşı dayanıklılık kazanmasına hem de zararının doğal biyolojik kontrol mekanizmasının bozulmasına sebep olmaktadır (Lee, 1990). $\mathrm{Bu}$ pestisitler kırmızı örümceklerin en etkili doğal düşmanları arasında yer alan Phytoseiulus persimilis Athias-Henriot gibi hedef olmayan organizmalar, çevre ve insan sağlığı üzerinde de ciddi olumsuz etkiler yaratmaktadır (Hayes ve Laws, 1991). Karşılaşılan bu problemler kırmızı örümceklere spesifik, kolay üretilebilen ve uygulanabilen, çevre, insan sağllğ 1 ve doğal düşmanlar gibi hedef olmayan organizmalara zararlı etkileri bulunmayan alternatif bileşiklerin geliştirilmesi ihtiyacını ortaya çıkarmaktadır. Bitkilerden elde edilen ekstraktların zararlıların doğal düşmanlarına karşı genel olarak çok düşük seviyede olumsuz etkileri bulunmaktadır (Bostanian ve ark., 2005; Isman, 2006). Bu bağlamda bitkilerden elde edilen bileşiklerin kırmızı örümcekler ile mücadelede pestisitlere alternatif kaynaklar olarak geliştirilmesi önem arz etmektedir.

$\mathrm{Bu}$ çalışmada tere (Lepidium sativum L.), roka (Eruca vesicaria Mill.), yarpuz (Mentha pulegium L.), fesleğen (Ocimum basilicum L.) ve biberiye (Rosmarinus officinalis L.) ekstraktlarının T. urticae'nin nimf ve ergin bireyleri üzerine insektisit etkisi yaprak daldırma yöntemi kullanılarak belirlenmiştir.

\section{Materyal ve Yöntem}

Denemelerde kullanılan T. urticae bireyleri, Çanakkale ili tarım alanlarından toplandıktan sonra $25 \pm 2{ }^{\circ} \mathrm{C}, \% 70 \pm 10$ orantılı nem ve $16: 8$ 1şıklandırma süresine ayarlı Çanakkale Onsekiz Mart Üniversitesi Ziraat Fakültesi Bitki Koruma Bölümü Akaroloji Laboratuvarı İklim Odasında fasulye (Phaseolus vulgaris L.) bitkileri üzerinde yetiştirilen popülasyonlardan nimf ve ergin bireyler elde edilmiştir. Çalışmada kullanılan bitkilerden yarpuz (Mentha pulegium L.), fesleğen (Ocimum basilicum L.) ve biberiye (Rosmarinus officinalis L.) ekstraktları Telci ve ark. (2010)'nın belirttiği yönteme göre laboratuarda oda sıcaklığında ve direkt güneş almayan ortamda kurutulduktan sonra toz haline getirilen bitki örnekleriden Neo-Clevenger aparatı kullanılarak distilasyon işlemi 
gerçekleştirilmiş ve elde edilen uçucu yağlar denemede kullanılıncaya kadar $+4^{\circ} \mathrm{C}$ 'de saklanmıştır. Tere (Lepidium sativum L.), roka (Eruca vesicaria Mill.) ekstraktlarının elde edilmesinde Gökçe ve ark. (2007)'nın belirttiği yönteme göre kuru örneklerin çözücü içerisinde 48 saat boyunca çalkalanması ve sonrasında süzülmesi sonucu elde edilen bileşiklerdeki çözücüler rotary evaporator yardımıyla uzaklaştırılarak bitki ekstraktları hazırlanmış ve $+4^{\circ} \mathrm{C}$ 'de saklanmıştır.

Ekstraktlarının T. urticae üzerindeki insektisit etkisini belirlemek amacıyla zararlının nimf ve ergin dönemlerine yaprak disk daldırma yöntemine göre uygulama yapılmıştır. Laboratuvar denemeleri özel olarak tasarlanan $5 \mathrm{~cm}$ çapındaki plastik petrilerde gerçekleştirilmiştir. Yaprak disklerin uzun süre taze kalmasını sağlamak amacıyla petrilerin taban kısımlarına nemlendirilmiş pamuk ve onun üzerine kurutma kâğıdı serilerek fasulye bitkisinden elde edilen yaprak diskleri yerleştirilmiştir. Petrilerin içerisinde nem birikmesini engellemek amacıyla petri kaplarının kapak kısımlarında delikler açılarak kırmızı örümceklerin dışarıya çıkmasını engellemek amacıyla da tül ile kapatılmıştır. İnsektisit etki denemeleri 5 tekerrür olacak şekilde yürütülmüştür. Yaprak diskleri ekstraktların farklı konsantrasyonlarında yaprak disk daldırma yöntemine göre 3-5 sn tutulmuş ve daha sonra kuruması için yaklaşık 15 dakika bekletilmiştir. Kontrol guruplarında ise \%0.3 Tween 20 içeren saf su kullanılmıştır. Yaprak diskleri kuruduktan sonra petri kaplarına alınmış ve her bir yaprak diski üzerine 10 adet ergin dişi $T$. urticae bırakılmıştır. Ölü ve canlı bireylerin sayımları 24, 48, 72 ve 96. saatlerde yapılarak bilgiler kaydedilmiştir.

Denemelerden elde edilen verilerle MiniTab 17 programı kullanılarak istatistik analiz yapılmıştır. Etki Abbot formülüne göre hesaplanmıştır (Abbott, 1925). Bu formüle göre Düzeltilmiş Yüzde Ölüm Oranı= [(A-B) / A] (A: Kontrolde canlı birey sayısı, B: Uygulama dozundaki canlı birey sayısı) olacak şekilde kontrolde meydana gelen ölümle düzeltilmiştir. Elde edilen ham veriler varyans analizine tabi tutulmuş (One-Way ANOVA) ve her ekstrakt için uygulanan konsantrasyonlar kendi aralarında karşılaştırılarak değerlendirilmiştir. Farklı bulunan değerlere Tukey Testi uygulanmıştır.

\section{Bulgular ve Tartışma}

$\mathrm{Bu}$ çalş̧mada tere (Lepidium sativum L.), roka (Eruca vesicaria Mill.), yarpuz (Mentha pulegium L.), fesleğen (Ocimum basilicum L.) ve biberiye (Rosmarinus officinalis L.) ekstraktlarının T. urticae'nin nimf ve ergin bireyleri üzerine insektisit etkisi yaprak daldırma yöntemi kullanılarak belirlenmiştir. Bitki ekstraktlarının T. urticae'nin nimf dönemi üzerindeki ölüm oranları ve etkileri Çizelge 1'de verilmiştir. T. urticae'nin nimf dönemi üzerinde en yüksek etkiyi $R$. officinalis ekstraktının \%12'lik konsantrasyonu 96. saat sonunda göstermiştir. Bu süre sonunda ekstraktın zararlı üzerinde \%68 oranında ölüm meydana getirdiği ve istatiksel olarak diğer dozlardan farklı olduğu belirlenmiştir $(\mathrm{P}<0,05)$. L. sativum, E. vesicaria ve M. pulegium ekstraktların ise aynı dozları 96. saat sonunda T. urticae nimfleri üzerinde \%54 ölüm meydana getirmiştir. Ekstraktların dozları ve süreler incelediğinde bitkisel ekstrakların T. urticae'nin nimf dönemleri üzerindeki etkilerinin dozlar ve süre arttığında ölüm oranlarının da artış gösterdiği belirlenmiştir. Bütün ekstraktların 4 farklı dozunda da en yüksek ölüm oranları ve etkiler 96. saat sonunda yapılan sayımlarda belirlenmiş ve süre ilerledikçe ekstraktın etkisinin artış gösterdiği belirlenmiştir. Bitkilerden elde edilen uçucu yağlarda bulunan monoterpenler bitkilerde anatomik ve fizyolojik bazı değişikliklere sebep olan etkilere sahiptir. Yürütülen çalışmalarda böcekler üzerinde önemli etkilere sahip olan bazı bitki ekstraktlarının aynı zamanda fitotoksik etkilerde gösterdiği bildirilmiştir (Liu ve ark., 2006). Bu çalışmada özellikle ekstraktların \%12'lik konsatrasyonlarının süre geçtikçe bitki üzerinde fitotoksik etki göstermeye başladığı da denemeler sırasında gözlenmiştir (Çizelge 1). Bu denemelerde ekstraktların muamele edildiği üzerinde kırmızı örümceklerin bulunduğu fasulye yaprak disklerinde 96. saatten sonra zamanla çürümeler ve deformasyonlar oluşmaya başladığı gözlenmiştir.

Bitki ekstraktlarının T. urticae ergin dönemi üzerindeki ölüm oranı ve etkisi \%1, 3, 6 ve 12 konsantrasyonlarında yaprak disk daldırma yöntemi kullanılarak belirlenmiş ve elde edilen bulgular Çizelge 2'de verilmiştir. Ektsraktların T. urticae üzerindeki en yüksek ölüm oranı 96. saat sonunda $R$. officinalis ekstraktında \%96 olarak belirlenmiş ve istatistik olarak diğer konsantrasyonlardan farklı olduğu tespit edilmiştir $(\mathrm{P}<0,05)$. Ekstraktların T. urticae üzerine en düşük ölüm oranı ise E. vesicaria ekstraktının \%1'lik konsantrasyonunda 24. saat sonunda yapılan sayımlarda \%4 olarak tespit edilmiştir. Ekstraktlar T. urticae'nin ergin bireyleri üzerindeki ölüm oranlarına göre $R$. officinalis $>M$. pulegium $>O$. basilicum $>$ E. vesicaria $>$ L. sativum olarak sıralanmıştır. Farklı dozlarda uygulanan bitki 
ÇOMÜ Zir. Fak. Derg. (COMU J. Agric. Fac.)

2019: 7 (1): 137-144

ISSN: $2147-8384$ / e-ISSN: $2564-6826$

doi: $10.33202 /$ comuagri.547474

ekstraktlarının ölüm oranları ve göstermiş oldukları etkilerinin konsantrasyonlar ve süre arttıkça artış gösterdiği gözlenmiştir (Çizelge 2).

Çizelge 1. Bitki ekstraktlarının Tetranychus urticae nimfleri üzerine insektisit etkisi (Ort. \pm S.H.)

\begin{tabular}{|c|c|c|c|c|c|c|c|c|c|c|c|c|}
\hline & \multicolumn{3}{|r|}{ 24. Saat } & \multicolumn{4}{|c|}{ 48. Saat } & \multicolumn{2}{|r|}{ 72. Saat } & \multicolumn{3}{|r|}{ 96. Saat } \\
\hline & Kons. & $\begin{array}{c}\text { Ölüm } \\
\text { Oranı } \\
(\%)\end{array}$ & $\begin{array}{l}\text { Etki* } \\
(\%)\end{array}$ & & $\begin{array}{l}\text { Ölüm } \\
\text { Oran1 } \\
(\%)\end{array}$ & $\begin{array}{l}\text { Etki } \\
(\%)\end{array}$ & & $\begin{array}{l}\text { Ölüm } \\
\text { Oranı } \\
(\%)\end{array}$ & $\begin{array}{l}\text { Etki } \\
(\%)\end{array}$ & & $\begin{array}{c}\text { Ölüm } \\
\text { Oranı } \\
(\%)\end{array}$ & $\begin{array}{l}\text { Etki } \\
(\%)\end{array}$ \\
\hline & 1 & 4 & $4,0 \pm 5,48$ & $\mathrm{a}$ & 6 & $6,0 \pm 5,48$ & $\mathrm{~b}$ & 14 & $4,4 \pm 6,09$ & $\mathrm{~b}$ & 24 & $5,0 \pm 6,85$ \\
\hline Lepidium & 3 & 6 & $6,0 \pm 5,48$ & $\mathrm{a}$ & 16 & $16,0 \pm 5,48$ & $a b$ & 24 & $15,5 \pm 9,94$ & $a b$ & 38 & $22,5 \pm 10,46$ \\
\hline \multirow[t]{2}{*}{ sativum } & 6 & 10 & $10,0 \pm 7,07$ & $\mathrm{a}$ & 22 & $22,0 \pm 4,47$ & $\mathrm{a}$ & 28 & $20,0 \pm 4,97$ & $\mathrm{a}$ & 50 & $37,5 \pm 8,84 \mathrm{ab}$ \\
\hline & 12 & 10 & $10,0 \pm 7,07$ & $\mathrm{a}$ & 18 & $18,0 \pm 8,37$ & $\mathrm{a}$ & 28 & $20,0 \pm 4,97$ & $\mathrm{a}$ & 54 & $42,5 \pm 6,85 \quad \mathrm{a}$ \\
\hline \multirow{4}{*}{$\begin{array}{l}\text { Eruca } \\
\text { vesicaria }\end{array}$} & 1 & 6 & $6,0 \pm 5,48$ & $\mathrm{a}$ & 10 & $12,0 \pm 4,47$ & $\mathrm{a}$ & 24 & $15,5 \pm 14,91$ & $\mathrm{a}$ & 32 & $24,4 \pm 9,30$ \\
\hline & 3 & 6 & $6,0 \pm 5,48$ & $\mathrm{a}$ & 14 & $14,0 \pm 5,48$ & $\mathrm{a}$ & 22 & $13,3 \pm 9,30$ & $\mathrm{a}$ & 32 & $24,4 \pm 9,30$ \\
\hline & 6 & 8 & $8,0 \pm 4,47$ & $\mathrm{a}$ & 18 & $18,0 \pm 8,37$ & $\mathrm{a}$ & 24 & $17,8 \pm 6,09$ & $\mathrm{a}$ & 44 & $37,8 \pm 6,09 \mathrm{ab}$ \\
\hline & 12 & 12 & $12,0 \pm 8,37$ & $\mathrm{a}$ & 20 & $20,0 \pm 7,07$ & $\mathrm{a}$ & 30 & $22,2 \pm 11,11$ & $\mathrm{a}$ & 54 & $48,9 \pm 6,09 \quad \mathrm{a}$ \\
\hline \multirow{4}{*}{$\begin{array}{l}\text { Ocimum } \\
\text { basilicum }\end{array}$} & 1 & 6 & $6,0 \pm$ & $\mathrm{a}$ & 14 & $4,4 \pm 6$ & $\mathrm{c}$ & 24 & $15,5 \pm$ & $\mathfrak{a}$ & 36 & $20,0=$ \\
\hline & 3 & 12 & $12,0 \pm 8,37$ & $\mathrm{a}$ & 18 & $8,9 \pm 4,97$ & $b c$ & 26 & $17,8 \pm 6,09$ & $\mathrm{a}$ & 38 & $22,5 \pm 5,59$ \\
\hline & 6 & 16 & $16,0 \pm 8,94$ & $\mathrm{a}$ & 24 & $15,5 \pm 6,09$ & $a b$ & 30 & $22,2 \pm 7,86$ & $\mathrm{a}$ & 54 & $42,5 \pm 6,85$ \\
\hline & 12 & 20 & $20,0 \pm 10,00$ & $\mathrm{a}$ & 28 & $20,0 \pm 4,97$ & $\mathrm{a}$ & 34 & $26,6 \pm 6,09$ & $\mathrm{a}$ & 62 & $52,5 \pm 5,59$ \\
\hline \multirow{4}{*}{$\begin{array}{l}\text { Mentha } \\
\text { pulegium }\end{array}$} & 1 & 6 & $6,0 \pm 5,48$ & $\mathrm{~b}$ & 10 & $10,0 \pm 7,07$ & $\mathrm{~b}$ & 26 & $26,0 \pm 5,48$ & $\mathrm{c}$ & 34 & $26,6 \pm 9,94$ \\
\hline & 3 & 6 & $6,0 \pm 5,48$ & $\mathrm{~b}$ & 12 & $12,0 \pm 8,37$ & $b$ & 32 & $32,0 \pm 4,47$ & bc & 42 & $35,5 \pm 4,97 \mathrm{bc}$ \\
\hline & 6 & 8 & $8,0 \pm 4,47$ & $a b$ & 28 & $28,0 \pm 4,47$ & $\mathrm{a}$ & 38 & $38,0 \pm 4,47$ & $a b$ & 46 & $40,0 \pm 6,09 \mathrm{ab}$ \\
\hline & 12 & 18 & $18,0 \pm 8,37$ & $\mathrm{a}$ & 32 & $32,0 \pm 4,47$ & $\mathrm{a}$ & 44 & $44,0 \pm 5,48$ & $\mathrm{a}$ & 54 & $48,9 \pm 6,09 \quad \mathrm{a}$ \\
\hline \multirow{4}{*}{$\begin{array}{l}\text { Rosmarinus } \\
\text { officinalis }\end{array}$} & 1 & 14 & $14,0 \pm 5,48$ & $\mathrm{a}$ & 24 & $24,0 \pm 5,48$ & $\mathrm{~b}$ & 28 & $28,0 \pm 4,47$ & $\mathrm{c}$ & 34 & $17,5 \pm 6,85$ \\
\hline & 3 & 16 & $16,0 \pm 5,48$ & $\mathrm{a}$ & 24 & $24,0 \pm 5,48$ & $b$ & 28 & $28,0 \pm 4,47$ & $\mathrm{c}$ & 36 & $20,0 \pm 6,85$ \\
\hline & 6 & 20 & $20,0 \pm 7,07$ & $\mathrm{a}$ & 38 & $34,0 \pm 5,48$ & $a b$ & 38 & $38,0 \pm 4,47$ & $\mathrm{~b}$ & 48 & $37,5 \pm 8,84$ \\
\hline & 12 & 22 & $22,0 \pm 8,37$ & $\mathrm{a}$ & 42 & $42,0 \pm 8,37$ & $\mathrm{a}$ & 56 & $56,0 \pm 5,48$ & $\mathrm{a}$ & 68 & $60,0 \pm 5,59$ \\
\hline
\end{tabular}

*Aynı sütun içerisinde ayrı harflerle gösterilen ortalamalar arasındaki fark istatistiki olarak önemli bulunmuştur $(\mathrm{P}<0,05)$.

Çizelge 2. Bitki ekstraktlarının Tetranychus urticae ergin bireyleri üzerine insektisit etkisi (Ort. \pm S.H.)

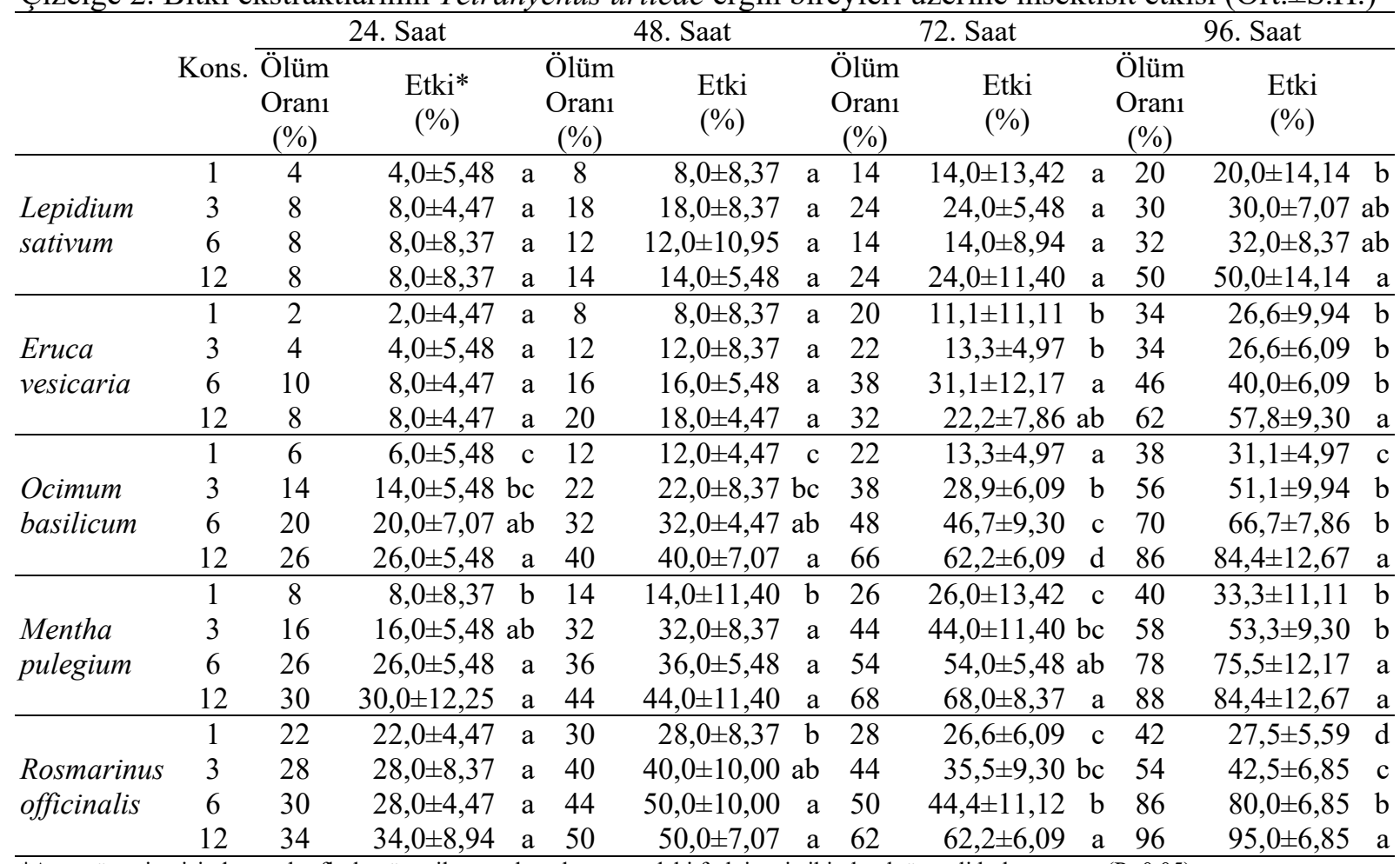

*Aynı sütun içerisinde ayrı harflerle gösterilen ortalamalar arasındaki fark istatistiki olarak önemli bulunmuştur ( $<<0,05)$. 
Bitkilerden elde edilen ekstraktlar uzun yıllardır tarımsal ürünlere zarar veren böceklere karşı mücadelede yaygın bir şekilde kullanılmaktadır. Fakat II. Dünya Savaşı'ndan itibaren tarımsal mücadelede kimyasalların yaygın bir şekilde kullanılması, kısa sürede iyi sonuçlar elde edilmesiyle bitkisel ekstraktlara olan ilgi azalmıştır. Kimyasal maddelerin tarımsal üretimde uzun süre kullanılmasının çevre ve insan sağlığında ciddi zararlı etkiler yaratmasıyla günümüzde yine alternatif mücadele yöntemlerine yönelme başlamıştır. Kimyasallara karşı kullanılan alternatif mücadele yöntemlerinin başında bitkilerden elde edilen ekstraktlar gelmektedir.

$\mathrm{Bu}$ çalışma sonucunda bitki ekstraktlarının İki noktalı kırmızıörümcek T. urticae'nin değişik biyolojik dönemleri üzerine konsantrasyonlara ve uygulama sürelerine bağlı olarak değişik oranlarda etkilerinin olduğu belirlenmiştir. Ekstraktlar arasında T. urticae'nin hem nimf hem de ergin dönemi üzerine $R$. officinalis, $M$. pulegium ve $O$. basilicum ekstraktlarının \%12'lik konsantrasyonlarının yüksek oranda insektisit etki gösterdiği belirlenmiştir. Bu sonuçları Yorulmaz Salman ve ark. (2015), Yorulmaz Salman ve ark. (2014) ve Topuz ve Madanlar (2011)'in yaptığı çalışmalar da elde edilen sonuçlar desteklemektedir. Mevcut çalışmada $L$. sativum ve E. vesicaria ekstraktlarının da $T$. urticae'nin değişik dönemleri üzerine orta derecede insektisit etkisinin bulunduğu tespit edilmiştir.

Bitkilerden elde edilen ekstraktların tarımsal zararlılar ile mücadele kullanım olanaklarını araştıran ve sonuçları bitkilerden elde edilen bileşiklerin umut vaat ettiğini kanıtlayan çok sayıda çalışma hem ülkemizde hem de dünyada yürütülmüştür (Gökçe ve ark., 2007; Wang ve ark., 2007; Iş1k ve Görür 2009; Erdoğan ve ark., 2010; Erdoğan ve Toros, 2010; Sertkaya ve ark., 2010; Topuz ve Madanlar, 2011; Çam ve ark., 2012; Karakoç ve Gökçe, 2012; Motazedian ve ark., 2012; Ebrahimi ve ark., 2013; Karakoç ve Gökçe, 2013; Akyazı ve ark., 2015; Alkan ve ark., 2015; Asiry, 2015; Erdoğan, 2015; Chen ve Dai, 2015; Selimoğlu ve ark., 2015; Yorulmaz Salman ve ark., 2015; Kasap ve ark., 2016; Pavela, 2016). Ekstraktların zararlılar üzerindeki farklı etkilerinin incelendiği çalışmalarda bu bileşiklerin zararlılara karşı kullanım potansiyelinin yüksek olduğu ortaya konmaktadir.

\section{Sonuç ve Öneriler}

Sonuç olarak bu çalışmada araştırılan L. sativum, E. vesicaria, M. pulegium, Ocimum basilicum ve $R$. officinalis bitkilerinden elde edilen ekstraktların \%1, 3, 6 ve 12'lik konsantrasyonlarının zararlı akar T. urticae nimf ve ergin dönemleri üzerine farklı oranlarda etkilerinin bulunduğu belirlenmiştir. Bu sonuçlara dayanarak doğada zaten hâlihazırda bulunan bitkilerden elde edilen ekstraktların zararlılar ile mücadele amacıyla kullanımı açısından önemli bir potansiyele sahip olduğu belirlenmiştir. Günümüzde kullanılan kimyasal bileşiklerin hem çevre ve insan sağlığı hem de hedef olmayan faydalı organizmalar üzerindeki olumsuz etkileri göz önüne alındığında bitki ekstraktlarının bu potansiyeli daha da önemli hale gelmektedir. Hem bu çalışmada araştırılan hem de doğada var olan birçok bitkiden elde edilecek ekstraktların tarımda ekonomik kayıplara sebep olan birçok zararlının değişik biyolojik dönemleri üzerindeki etkilerinin hem arazi hem de laboratuar koşullarında araştırılmasının bu ekstraktların zararlılar ile mücadele de kullanım olanaklarını arttıracağı düşünülmektedir.

Not: Bu çalışma 9-12 Mayıs 2018 tarihlerinde Van, Türkiye'de düzenlenen 'International Agricultural Science Congress'de poster bildiri olarak sunulmuş ve bildiri kitabında özet bildiri olarak yayımlanmıştır.

\section{Teşekkür}

$\mathrm{Bu}$ çalışma Çanakkale Onsekiz Mart Üniversitesi Bilimsel Araştırma Projeleri Koordinasyon Birimince Desteklenmiş̧tir. Proje Numaras1: FBA-2016-926.

\section{Kaynaklar}

Abbott, W.S., 1925. A method of computing the effectiveness of an insecticide. Jounal of Economic Entomology. 18 (2): 265-267.

Akyazı, R., Soysal, M., Hassan, E., 2015. Toxic and repellent effects of Prunus laurocerasus L. (Rosaceae) extracts against Tetranychus urticae Koch (Acari: Tetranychidae). Turkish Journal of Entomology. 39 (4): 367-380.

Alkan, M., Gökçe, A., Kara, K., 2015. Antifeedant activity and growth inhibition effects of some plant extracts against larvae of Colorado potato beetle [Leptinotarsa decemlineata Say (Col: Chyrsomelidae)] under laboratory conditions. Turkish Journal of Entomology. 39 (4): 345-353. 
doi: $10.33202 /$ comuagri.547474

Asiry, K.A., 2015. Aphidicidal activity of different aqueous extracts of bitter apple Citrullus colocynthis (L.) against the bird cherry-oat aphid, Rhopalosiphum padi (L.) (Homoptera: Aphididae) under laboratory conditions. Journal of Animal \& Plant Sciences. 25 (2): 456-462.

Aslan, I., Özbek, H., Çalmaşur, Ö., Şahin, F., 2004. Toxicity of essential oilvapours to two greenhouse pests, Tetranychus urticae Koch and Bemesia tabaci Genn. Industrial Crops and Products, 19(2): 167-173.

Bostanian, N.J., Akalach, M., Chiasson, H., 2005. Effects of a chenopodium-based botanical insecticide/acaricide on Orius insidiosus (Hemiptera: Anthocoridae) and Aphidius colemanii (Hymenoptera: Braconidae). Pest Management Science, 61: 979-984.

Chen, Y., Dai, G., 2015. Acaricidal activity of compounds from Cinnamomum camphora (L.) Presl against the carmine spidermite, Tetranychus cinnabarinus. Pest Management Science. 71: 1561-1571.

Chiasson, H., Be'langer, A., Bostanian, N., Vincent, C., Poliquin, A., 2001. Acaricidal properties of Artemisia absinthium and Tanacetum vulgaren (Asteraceae) essential oils obtained by different methods of extraction. Journal of Economic Entomology, 94: 167-171.

Cutler, D.M., Miller, G., 2005. The role of public health improvements in health advances: the 20th century United States. Demography. 42 (1): 1-22.

Çam, H., Karakoç, Ö.C., Gökçe, A., Telci, İ., Demirtaş, İ., 2012. Farklı nane türlerine ait klonların uçucu yağlarının buğday biti [Sitophilus granarius L. (Coleoptera: Curculionidae)]'ne fumigant etkisi. Türkiye Entomoloji Dergisi. 36 (2): 255-263.

Derbalah, A.S., Keratrum, A.Y., El-Dewy, M.E., El-Shamy, E.H., 2013. Efficacy of some insecticides and plant extracts against Tetranychus urticae under laboratory conditions. Egyptian Journal of Plant Protection Research, 1(3): 47-69.

Ebrahimi, M., Safaralizade, M.H., Valizadegan, O., Amin, B.H.H., 2013. Efficacy of three plant essential oils, Azadirachta indica (Adr. Juss.), Eucalyptus camaldulensis (Dehn.) and Laurus nobilis (L.) on mortality cotton aphids, Aphis gossypii Glover (Hem: Aphididae). Archives of Phytopathology and Plant Protection. 46 (9): 1093-1101.

Erdoğan, P., 2015. Capsicum annuum L. (Solanaceae) ve Allium sativum L. (Amaryllidaceae) ekstraktlarının Myzus persicae (Sulzer) (Hemiptera:Aphididae) üzerine insektisit etkisi. Bitki Koruma Bülteni. 55 (4): 305-315.

Erdoğan, P., Saltan, G., Sever, B., 2010. Acı biber (Capsicum annum L.) ekstraktının iki noktalı kırmızı̈rümcek, Tetranychus urticae Koch (Arachnida: Tetranychidae)'ye akarisit etkisi. Bitki Koruma Bülteni. 50: 35 43.

Erdoğan, P., Toros, S., 2005. Melia azedarach L. (Meliaceae) ekstraktlarının Patates böceği [Leptinotarsa decemlineata Say (Col.: Chrysomelidae)] larvalarının gelişimi üzerine etkisi. Bitki Koruma Bülteni. 45 (1-4): 99-118.

Erdoğan, P., Toros, S., 2010. Azadirachta indica A. Juss ekstraktlarının Patates böceği [Leptinotarsa decemlineata Say (Col.: Chrysomelidae)]'ne beslenme engelleyici etkisi. Bitki Koruma Bülteni. 50 (4): 193-200.

Gökçe, A., Whalon, M.E., Çam, H., Yanar, Y., Demirtaş, İ., Gören, N., 2007. Contact and residual toxicities of 30 plant extracts to Colorado potato beetle larvae. Archives of Phytopathology and Plant Protection. 40 (6): 441-450.

Grant, S., Saphores, J., Feldman, D., Hamilton, A., Fletcher, T.D., Cook, P., Stewardson, M., Sanders, B., Levin, L., Ambrose, R., Deletic, A., Brown, R., Jiang, S., Rosso, D., Cooper, W., Marusic, I., 2012. Taking the "waste" out of "wastewater" for human water security and ecosystem sustainability. Science. 337: 681686.

Hayes, W.J.Jr., Laws, E.R. Jr., 1991. Handbook of pesticide toxicology, vol. 1. Academic, 1576 pp., San Diego, CA.

Islam, M.T., Haque, M.M., Naher, N., Parween, S., 2008. Effect of plant materials on developmental periods of two spotted spider mite Tetranychus urticae Koch (Acari: Tetranychidae). International Journal of Biological Sciences, 16: 121-124.

Isman, M.B., 2006. Botanical insecticides, deterrents, and repellents in modern agriculture and an increasingly regulated world. Annual Reviwer Entomology, 51: 45-66.

Iş1k, M., Görür, G., 2009. Aphidicidial activity of seven essential oils against the cabbage aphid, Brevicoryne brassicae L. (Hemiptera: Aphididae). Munis Entomology \& Zoology Journal. 4 (2): 424-431.

Jeppson, L.R., Keifer, H.H., Baker, E.W., 1975. Mites injurious to economic plants. University of California Pres, 615p., Berkeley, London,

Karakoç, Ö.C., Gökçe, A., 2012. Bitki ekstraktlarının Spodoptera littoralis (Lepidoptera: Noctuidae)'e olan kontak toksisiteleri. Türkiye Entomoloji Dergisi. 36 (3): 423-431.

Karakoç, Ö.C., Gökçe, A., 2013. Farklı bitki ekstraktlarının Spodoptera littoralis (Lepidoptera: Noctuidae) üzerinde beslenme engelleyici ve mide zehiri etkileri. Türkiye Entomoloji Dergisi. 37 (1): 73-80. 
Kasap, İ., Kök, Ş., Hassan, E., 2016. Effect of Fungatol and Gamma-T-ol from Melaleuca alternifolia (Maiden \& Betche) Cheel on Aphis gossypii Glover (Hemiptera: Aphididae) and Tetranychus urticae Koch (Acari: Tetranychidae). Turkish Journal of Entomology, 40 (2): 117-123.

Kök, Ş., Erdoğmuş, A., Koyun, A., Kasap İ., 2016. Melaleuca alternifolia (Myrtaceae)'dan Elde Edilen Fungatol ve Gamma-T-ol Ekstraktlarının Laboratuar Koşullarında Tetranychus urticae Koch (Acari: Tetranychidae)'ye Karşı Repellent Etkisi. ÇOMÜ Ziraat Fakültesi Dergisi, 4 (1): 93-98.

Lee, S.W., 1990. Studies on the pest status and integrated mite management in apple orchards. Ph.D. dissertation. Seoul National University, Suwon, Republic of Korea.

Liu, C.H., Mishra, A.K., Tan, R.X., Tang, C., Yang, H., Shen, Y.F., 2006. Repellent and insecticidal activities of essential oils from Artemisia princeps and Cinnamomum camphora and their effect onseed germination of wheat and broad bean. Bioresource Technology, 97: 1969-1973.

Liu, S.Q., Shi, J.J., Cao, H., Jia, F.B., Liu, X.Q., Shi, G.L., 2000. Survey of pesticidal component in plant, in entomology in China in 21th Century. Science and Technical Press. 1098-1104 p.

Martinez-Villar, E., Saenz-de-Cabezon, F., Moreno-Grijalba, F., Marco, V., Perez-Moreno, I., 2005. Effects of azadirachtin on the twospotted spider mite, Tetranychus urticae (Acari: Tetranychidae). Experimental and Applied Acarology, 35: 215-222.

Motazedian, N., Ravan, S., Bandani, A.R., 2012. Toxicity and repellency effects of three essential oils against Tetranychus urticae Koch (Acari: Tetranychidae). J. Agr. Sci. Tech., Vol. 14: 275-284.

Pavela, R., 2016. Acaricidal properties of extracts of some medicinal and culinary plants against Tetranychus urticae Koch. Plant Protection Science, 52(1): 54-63.

Selimoğlu, T., Gökçe, A., Yanar, D., 2015. Bazı bitki uçucu yağlarının Acanthoscelides obtectus (Say) (Coleoptera: Bruchidae) üzerindeki fumigant toksisiteleri. Türkiye Entomooji Dergiğsi. 39 (1): 109-118.

Sertkaya, E., Kaya, K., Soylu, S., 2010. Acaricidal activities of the essential oils from several medicinal plants against the carmine spider mite (Tetranychus cinnabarinus Boisd.) (Acarina: Tetranychidae). Industrial Crops and Products. 31: 107-112.

Telci, I., Demirtas, I., Bayram, E., Arabaci, O., Kaçar O., 2010. Environmental variation on aroma components of pulegone/piperitone rich spearmint (Mentha spicata L.). Industrial Crops and Products, 32, 588-592.

Thomas C.E. 1969. Transmission of tobacco ringspot virus by Tetranychus sp. Phytopathology, 59: 633-636.

Tomczyk, A., Suszko, M., 2011. The role of phenols in the influence of herbal extracts from Salvia officinalis L. and Matricaria chamomilla L. on two-spotted spider mite Tetranychus urticae Koch. Biological Letters, 48 (2): 193-205.

Topuz, E., Madanlar, N., 2011. Bazı bitkisel kökenli uçucu yağların Tetranychus cinnabarinus (Boisduval, 1867) (Acari: Tetranychidae) üzerine kontakt ve repellent etkileri. Türkiye Entomoloji Bülteni, 1 (2): 99-107.

Wang, Y.N., Shi, G.L., Zhao, L.L., Liu, S.Q., Yu, T.Q., Clarke, S.R., Sun, J.H., 2007. Acaricidal activity of Juglans regia leaf extracts on Tetranychus viennensis and Tetranychus cinnabarinus (Acari: Tetranychidae). Journal of Economic Entomology. 100 (4): 1298-1303.

Yang, H.Z., Li, Q., Lei, H.D., 2007. Research and application of botanical acaricides. Pesticide, 46, 81-85.

Yorulmaz Salman, S., Saritas, S., Kara, N., Ay, R., 2014. Acaricidal and ovicidal effects of Sage (Salvia officinalis L.) and Rosemary (Rosmarinus officinalis L.) (Lamiaceae) extracts on Tetranychus urticae Koch (Acari: Tetranychidae). Journal Of Agricultural Sciences, 20: 358-367.

Yorulmaz Salman, S., Saritas, S., Kara, N., Aydinli, F., Ay, R., 2015. Contact, repellency and ovicidal effects of four Lamiaceae plant essential oils against Tetranychus urticae Koch (Acari: Tetranychidae). TEOP, 18(4): $857-872$.

Zhang, Z., 2003. Mites of green houses: Identification, biology and control. CABİ Publishing, 244p., Wallingford.

Telci, I., Demirtas, I., Bayram, E., Arabaci, O., Kaçar O., 2010. Environmental variation on aroma components of pulegone/piperitone rich spearmint (Mentha spicata L.). Industrial Crops and Products, 32, 588-592.

Thomas C.E. 1969. Transmission of tobacco ringspot virus by Tetranychus sp. Phytopathology, 59: 633-636.

Tomczyk, A., Suszko, M., 2011. The role of phenols in the influence of herbal extracts from Salvia officinalis L. and Matricaria chamomilla L. on two-spotted spider mite Tetranychus urticae Koch. Biological Letters, 48 (2): 193-205.

Topuz, E., Madanlar, N., 2011. Bazı bitkisel kökenli uçucu yağların Tetranychus cinnabarinus (Boisduval, 1867) (Acari: Tetranychidae) üzerine kontakt ve repellent etkileri. Türkiye Entomoloji Bülteni, 1 (2): 99-107.

Wang, Y.N., Shi, G.L., Zhao, L.L., Liu, S.Q., Yu, T.Q., Clarke, S.R., Sun, J.H., 2007. Acaricidal activity of Juglans regia leaf extracts on Tetranychus viennensis and Tetranychus cinnabarinus (Acari: Tetranychidae). Journal of Economic Entomology. 100 (4): 1298-1303.

Yang, H.Z., Li, Q., Lei, H.D., 2007. Research and application of botanical acaricides. Pesticide, 46, 81-85. 
ÇOMÜ Zir. Fak. Derg. (COMU J. Agric. Fac.)

2019: 7 (1): 137-144

ISSN: $2147-8384$ / e-ISSN: 2564-6826

doi: $10.33202 /$ comuagri.547474

Yorulmaz Salman, S., Saritas, S., Kara, N., Ay, R., 2014. Acaricidal and ovicidal effects of Sage (Salvia officinalis L.) and Rosemary (Rosmarinus officinalis L.) (Lamiaceae) extracts on Tetranychus urticae Koch (Acari: Tetranychidae). Journal Of Agricultural Sciences, 20: 358-367.

Yorulmaz Salman, S., Saritas, S., Kara, N., Aydinli, F., Ay, R., 2015. Contact, repellency and ovicidal effects of four Lamiaceae plant essential oils against Tetranychus urticae Koch (Acari: Tetranychidae). TEOP, 18(4): $857-872$.

Zhang, Z., 2003. Mites of green houses: Identification, biology and control. CABİ Publishing, 244p., Wallingford. 